\title{
A Journey through Inculcating Preparation for Handling Medical Emergencies amongst Dental Personnel: The Validation of Medical Emergencies in Dental Practice Questionnaire (MEDPQ)
}

\author{
Amir Anuar Badrulhisham \\ Faculty of Dentistry, Universiti Teknologi MARA \\ Selangor, Malaysia. \\ intanbaizura3124@salam.uitm.edu.my \\ Muhammad Aiman Zairudin \\ Faculty of Dentistry, Universiti Teknologi MARA \\ Selangor, Malaysia
}

\author{
Izyan Hazwani Baharuddin \\ Faculty of Dentistry, Universiti Teknologi MARA \\ Selangor, Malaysia \\ Tengku Dr Intan Baizura Tengku Jamaluddin \\ Centre of Oral \& Maxillofacial Surgery Studies, \\ Faculty of Dentistry, Universiti Teknologi MARA \\ Selangor, Malaysia
}

\begin{abstract}
The objective of this study is to construct and validate a questionnaire regarding the assessment of perceived confidence, attitude and knowledge of dental undergraduates in handling medical emergencies in dental practice. A cross-sectional study was conducted on 82 dentists and clinical staff practicing in dental setting either in university campus-based or hospital-based around Malaysia by convenience sampling. The questionnaire was developed and undergone content validation by the experts from 7 Emergency Physicians, Faculty of Medicine, UiTM and 6 Oral and Maxillofacial Surgeons, Faculty of Dentistry, UiTM and face validation by 10 graduating dental students. Questionnaire consists of 6 parts and there were 38 cognitive questions in the form of Likert scale of 1 to 5. Participation in this research required implied consent. Data was analyzed using SPSS version 23.0. Construct Validation was determined by exploratory factor analysis (EFA) while reliability was determined by Cronbach's alpha. There are 3 questions to be validated. The Question 9 which consists of 11 items yielded a double-factor structure that demonstrated a high factor loading with a range of 0.703 to 0.983 and a good internal consistency (Cronbach's alpha $=\mathbf{0 . 9 1 8}$ ). The other two questions, Question 10 and 20, consists of single-factor structure with factor loading ranging from 0.784 to 0.934 and 0.805 to 0.892 respectively. In conclusion, Medical Emergencies in Dental Practice Questionnaire (MEDPQ) is valid and reliable to measure awareness and perceived confidence of dental personnel in handling medical emergencies.
\end{abstract}

Keywords-medical emergencies, questionnaire validation, dental practice, $M E D P Q$

\section{INTRODUCTION}

Colla et al (2005) and Sammer et al (2010) reported in their studies that by considering the risks for errors and aftermaths, the environment in which health care services are provided are considered a hazardous sector
$[1,2]$. Even though the risks and possible outcomes are explained, some events are inevitable. Fortunately, the occurrence of emergencies in dental setting is relatively low, but happens to be life-threatening [3]. Many organizations, governments and non-government bodies have created efforts in avoiding such events. In 2004, World Alliance for Patient Safety was launched by World Health Organization (WHO) to de-escalate the adverse events of unsafe health care, and strengthening the goal of "First do no harm" [4].

As a precautionary step, it is wise to monitor vital signs of medically challenged patients prior to conducting dental treatment as the procedures may cause systemic disturbances to the patient (e.g. local anesthesia). Acute medical emergencies may be predicted by the dentist, and the trend of the emergency and efficacy of preventive measures can be evaluated if monitoring was conducted [6].

In handling medical emergencies, dentists and clinical personnel is required to work hand in hand to efficiently overcome any unexpected event. According to a study conducted in Belgium (2013), almost half of the sample which is dentists never participated in Basic Life Support (BLS) training course [7]. Basic Life Support training is essential to dentists as per depicted, at least one medical emergency will occur in about $43.6 \%$ of dentists during their career [8].

Hence, the objective of this study is to construct and validate Medical Emergency in Dental Practice Questionnaire (MEDPQ) regarding the assessment of perceived confidence, attitude and knowledge of dental personnel in handling medical emergencies in a dental practice. 


\section{MATERIALS AND METHODS}

A cross-sectional study was conducted on 82 dentists and clinical personnel practicing in dental settings either in university campus-based or hospitalbased around Malaysia by convenience sampling. This study was approved by Ethics Committee of the Institute of Research Management and Innovation (IRMI), Universiti Teknologi MARA (600-IRMI $(5 / 1 / 6))$. Consents were obtained from sample prior to the survey.

\section{A. Selection of sample}

A total of 101 questionnaires were distributed via hard copy and online. Only 82 agreed to participate in the study and returned the questionnaires within the given deadline.

\section{B. Inclusion criteria}

Subjects must be dental healthcare personnel (dentist or clinical staff) with minimal 3 years of working experience at a dental practice in Malaysia and understand English proficiently, both in terms of reading and speaking.

\section{Sample size determination}

For exploratory factor analysis (EFA), the minimum suggested by Stevens (2002) was five subjects per variable. Given the MEDPQ module has 3 main cognitive questions which are questions 9,10 and 20.

\section{Preparation of questionnaire}

Preparation of MEDPQ was done during the first phase of the research. MEDPQ was designed with 9 demographic questions, 5 questions assessing on knowledge towards medical emergencies and 38 cognitive questions.

The questionnaire comprised of 6 parts. Part 1 of MEDPQ is for demographic characteristics of subjects; whilst Part 2 assessed the knowledge of subjects regarding medical emergencies. Part 3 of MEDPQ was identification of respondents' awareness of the available emergency equipment at their respective dental clinics. Part 4 surveyed the medical emergency training received, while Part 5 assessed the perception of subjects pertaining to management of medical emergencies. The final part of MEDPQ was entailed to estimate subject's perceived self confidence in management of medical emergencies.

The constructed questionnaire underwent content validation by 7 Emergency Physicians, Faculty of Medicine, UiTM and 6 Oral and Maxillofacial Surgeons, Faculty Dentistry, UiTM. Feedback gained was used to assess the relevance of questions, design of the questionnaire, grammar used in the questionnaire and estimated time spent to answer MEDPQ. MEDPQ was amended according to the expert feedback, and used in the face validation.

Face validation was done on 10 graduating dental students comprising of five males and five female students. The purpose of face validation was to test the reliability, design, grammar and time spent to answer the questionnaire. Results obtained from the face validation were used to improve MEDPQ to optimal level for subjects to answer in the second phase of the research.

Final amended version of MEDPQ went through construct validation by 82 dentists and clinical personnel, where 3 main cognitive questions in MEDPQ assessed the confidence level of subjects in handling medical emergencies at dental practice. Exploratory factor analysis (EFA) was used to investigate the structure and determine the validity of those three questions.

\section{E. Statistical analysis}

All analysis of the data obtained was done using IBM SPSS 24. Exploratory factor analysis (EFA) with principal axis factoring was used. Factors were extracted following scree plot with more than 1 Eigenvalue. Communalities are kept above 0.5. The reliability of internal consistency was determined using Cronbach's Alpha.

\section{RESULTS}

\section{A. Demographic data}

Of the 82 samples, 58 were female while the rest were male. Averagely aged $35( \pm 7)$. Majority $(90.2 \%)$ of the subjects are Malay with the rest being Indian, Bumiputera and others (Arabic, etc.). Level of education varies with postgraduate (MSc, MPhil, $\mathrm{PhD}$ ) being the highest $(67.1 \%)$ followed by undergraduate (17.1\%), Matriculation/STPM/Asasi/Diploma/Sijil (8.5\%), and high school (7.3\%).

\section{B. Knowledge}

In MEDPQ, the assessment of knowledge has definite answers. Participants were asked with closeended questions of "yes" or "no" answers.

In Part 2: Medical Emergencies, $94.9 \%$ of the participants answered cardiac arrest as one of the medical emergencies, which is the highest score, followed by excessive bleeding $(93.5 \%)$ and severe angina $(90.8 \%)$. Only $16.9 \%$ of the participants considered hypoglycemia as a medical emergency which accounts as the lowest percentage of corrected answer. This is probably due to the confusion of the term "hypoglycemia" and "hypoglycemic shock".

In Part 3: Availability of Emergency Equipment at Dental Clinic, $56.9 \%$ of the participants answered correctly for question 11 which is to check the emergency trolley every week. While in question 12 , $83.3 \%$ agreed with the correct answer which is changing the oxygen cylinder when the pressure gauge is within red zone.

While in Part 5: Management of Medical Emergencies, $61.4 \%$ of the participants knew the abbreviation of DRCAB (AHA 2010/2015) in question 18 and answered correctly. More than half of the respondents knew when to stop Cardiopulmonary Resuscitation (CPR). 


\section{Exploratory factor analysis (EFA)}

Question 9 measured the awareness of the subjects towards the availability of emergency equipment in dental clinic. The question yielded two factors with an Eigenvalue of 6.028 and 1.949. A valid and good convergent validity is indicated by a good strength of factor loading (Cronbach \& Meehl, 1955). The range of communalities is from 0.573 to 0.891 . By referring to Table I, the EFA of this question measured two factors, one being equipment found in emergency trolley in primary care clinics and the other one being other equipment in medical emergency departments.

TABLE I. QUESTION 9 AWARENESS OF AVAILABILITY OF

\begin{tabular}{|c|c|c|c|c|}
\hline \multicolumn{5}{|c|}{ EMERGENCY EQUIPMENT AT DENTAL CLINIC } \\
\hline Factor & Item & $\begin{array}{c}\text { Factor } \\
\text { Loading }\end{array}$ & $\begin{array}{c}\text { Com- } \\
\text { munality }\end{array}$ & $\begin{array}{l}\text { Cron- } \\
\text { bach's } \\
\text { Alpha } \\
\end{array}$ \\
\hline $\begin{array}{l}\text { Equipment } \\
\text { in } \\
\text { emergency } \\
\text { trolley in } \\
\text { primary } \\
\text { care }\end{array}$ & $\begin{array}{l}\text { i. High flow } \\
\text { mask } \\
\text { ii. Oxygen } \\
\text { tubing } \\
\text { iii. Bag valve } \\
\text { mask } \\
\text { iv. Oxygen } \\
\text { cylinder } \\
\text { v. IV cannula } \\
\text { vi. Automated } \\
\text { external } \\
\text { defibrillator } \\
\text { (AED) with } \\
\text { pads } \\
\text { vii.Extra } \\
\text { defibrillator } \\
\text { pads }\end{array}$ & $\begin{array}{l}0.905 \\
0.965 \\
0.983 \\
\\
0.741 \\
\\
0.703 \\
0.818\end{array}$ & $\begin{array}{l}0.814 \\
0.858 \\
0.891 \\
\\
0.736 \\
\\
0.654 \\
0.695\end{array}$ & 0.938 \\
\hline $\begin{array}{l}\text { Other } \\
\text { clinical } \\
\text { equipment }\end{array}$ & $\begin{array}{ll}\text { viii. } & \text { PPE - } \\
& \text { gloves, } \\
& \text { aprons, eye } \\
\text { protection } \\
\text { ix. } & \text { Stethoscope } \\
\text { x. Alcohol } \\
\text { swab } \\
\text { xi. } & \text { Adhesive } \\
\text { tapes }\end{array}$ & $\begin{array}{l}0.714 \\
0.885 \\
\\
0.890\end{array}$ & $\begin{array}{l}0.528 \\
0.821 \\
0.751\end{array}$ & 0.834 \\
\hline
\end{tabular}

Question 10 measured the awareness of the availability of emergency drugs in emergency trolley at the subjects' clinic. Question generated single distinct factor which represent drug in emergency trolley as mentioned in Table II. Generated factor showed an Eigenvalue of 10.607 and good strength of factor loadings ranged from 0.784 to 0.934 . Communalities ranged from 0.615 to 0.847 .

In question 20 perceived confident in handling medical emergencies is measured. One factor was yielded from the question with Eigenvalue of 9.878 . The factor is medical emergencies as mentioned in Table III. Generated factor loading was showing good strength ranged from 0.805 to 0.928 . Communalities ranged from 0.615 to 0.872 .

\section{Reliability by internal consistency (Cronbach's alpha)}

Cronbach's alpha of the three questions, Q9, Q10 and Q20 all showed a good internal consistency. Q9 has Cronbach's alpha of 0.938 for the first factor and 0.834 for the second factor. While Q10 and Q20, with single factor, possessed Cronbach's alpha of 0.975 and 0.973 .

TABLE II. QUESTION 10 AWARENESS OF AVAILABILITY OF EMERGENCY DRUGS AT IN EMERGENCY TROLLEY

\begin{tabular}{|c|c|c|c|c|}
\hline Factor & Item & $\begin{array}{l}\text { Factor } \\
\text { loading }\end{array}$ & $\begin{array}{c}\text { Com- } \\
\text { munality }\end{array}$ & $\begin{array}{l}\text { Cron- } \\
\text { bach's } \\
\text { Alpha }\end{array}$ \\
\hline $\begin{array}{l}\text { Emergency } \\
\text { Drugs }\end{array}$ & 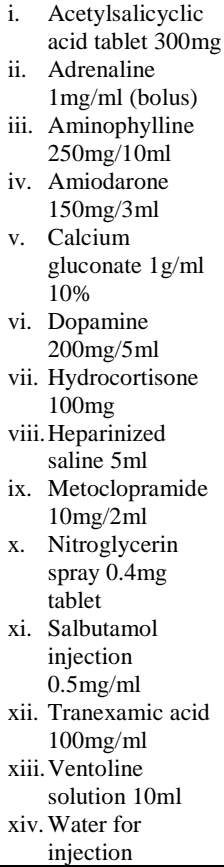 & $\begin{array}{l}0.860 \\
0.918 \\
0.866 \\
0.784 \\
0.868 \\
0.920\end{array}$ & $\begin{array}{l}0.739 \\
0.842 \\
0.750 \\
0.615 \\
0.753 \\
0.847\end{array}$ & 0.975 \\
\hline
\end{tabular}

TABLE III. QUESTION 20 ESTIMATION OF SELF-EFFICACY IN

\begin{tabular}{|c|c|c|c|c|}
\hline Factor & Item & $\begin{array}{l}\text { Factor } \\
\text { loading }\end{array}$ & $\begin{array}{c}\text { Com- } \\
\text { munality }\end{array}$ & $\begin{array}{l}\text { Cron- } \\
\text { bach's } \\
\text { alpha }\end{array}$ \\
\hline $\begin{array}{l}\text { Medical } \\
\text { emergencies }\end{array}$ & 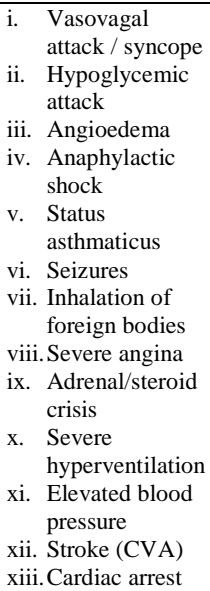 & $\begin{array}{l}0.837 \\
0.869 \\
0.805 \\
0.892 \\
0.864 \\
0.860 \\
0.892 \\
0.864 \\
0.860 \\
0.892 \\
0.880 \\
0.890 \\
0.857\end{array}$ & $\begin{array}{l}0.701 \\
0.755 \\
0.649 \\
0.796 \\
0.746 \\
\\
0.740 \\
0.796 \\
0.736 \\
0.860 \\
0.797 \\
0.774 \\
0.792 \\
0.735\end{array}$ & 0.973 \\
\hline
\end{tabular}

\section{DISCUSSION}

Limitation of study was the questionnaire constructed in English. Participants must have sufficient vocabulary to understand certain complex terms. We propose that a Bahasa Melayu version of MEDPQ should be constructed for future research especially to assess clinical personnel.

Based on EFA conducted, it is proven that Medical Emergencies in Dental Practice Questionnaire 
(MEDPQ) are valid and reliable to be used in further study regarding.

\section{ACKNOWLEDGEMENTS}

Our sincere gratitude goes to the Emergency Physicians, Faculty of Medicine, Oral and Maxillofacial Surgeons and 10 graduating students from Faculty of Dentistry, Universiti Teknologi MARA for their contribution throughout this study.

\section{REFERENCES}

[1] J.B. Colla, A.C. Bracken, L.M. Kinney, et al., "Measuring patient safety: a review of surveys," Qual. Saf. Health Care, vol. 14, pp. 364-366, 2005.

[2] C.E. Sammer, K. Lykens, K.P. Singh, et al., "What is patient safety culture? A review of the literature," J. Nurs. Scholar, vol. 42, pp. 156-165, 2010.
[3] L. Place, Medical emergencies in dental practice. Dublin Dental Hospital, 2017.

[4] World Health Organization. (2017, January 2) World alliance for patient safety. Available: http://www.who.int/patientsafety/en.

[5] N. Yamalik, B.P. Pe, (2016, December 24) Patient safety and dentistry: what do we need to know? Fundamentals of patient safety, the safety culture and implementation of patient safety measures in dental practice. Available: https://doi.org/10.1111/j.1875-595X.2012.00119.x

[6] H. Fukayama, J.A. Yagiela, "Monitoring of vital signs during dental care," pp. 102, 2006.

[7] L.A.M Marks, C. Parys, M. Van, Coppens, L. Herregods. (2017, January 2) Awareness of dental practitioners to cope with a medical emergency: a survey in Belgium. Available: https://doi.org/10.1111/idj.12046

[8] L.J. Cronbach, P.E. Meehl, "Construct validity in psychological tests,” Psychological Bulletin, vol. 52(4), pp. 281, 1955. 